\title{
Knowledge, Attitude and Perception of West Africans Towards COVID-19: A Survey to Inform Public Health Intervention
}

Aniefiok John Udoakang ( $\square$ aniefiokjohn.udoakang@ucad.edu.sn )

University of Ghana

Alexandra Lindsey Djomkam Zune

University of Ghana

Kesego Tapela

University of Ghana

Owoicho Oloche

University of Ghana

Ifeoluwa Kayode Fagbohun

Nigerian Institute of Medical Research

Claudia Adzo Anyigba

University of Ghana

Matt Lowe

Society for the Study of Women's Health (SSWH), Old Yundum

Nora Nghochuzie Nganyewo

University of Ghana

Bineta Keneme

Equipe Génétique et Gestion pour les Populations, Université Cheikh Anta Diop de Dakar

Frances Ngozi Olisaka

Benson Idahosa University

Agatha Nkem Henry-Ajala

University of Lagos

Mary Aigbiremo Oboh

Medical Research Council Unit, The Gambia at the London School of Hygiene and Tropical Medicine,

Banjul

Lily Paemka

University of Ghana

Lucas N Amenga-Etego

University of Ghana 
Keywords: COVID-19, West Africa, Knowledge, Attitude and Perception, Vaccine acceptance

Posted Date: September 8th, 2021

DOI: https://doi.org/10.21203/rs.3.rs-812134/v1

License: (c) (1) This work is licensed under a Creative Commons Attribution 4.0 International License. Read Full License

Version of Record: A version of this preprint was published at BMC Public Health on March 5th, 2022. See the published version at https://doi.org/10.1186/s12889-022-12814-9. 


\section{Abstract}

Background: The first case of the novel coronavirus disease-2019 (COVID-19) in West Africa was first confirmed in Nigeria in February 2020. Since then, several public health interventions and preventive measures have been implemented to curtail transmission of the causative agent, the Severe Acute Respiratory Syndrome Coronavirus 2 (SARS-CoV-2). Therefore, this study was performed to assess the knowledge, attitudes, and perceptions of West Africans towards COVID-19.

Methods: An online survey was conducted between 29 September to 29 October 2020 among West Africans. Thirty-three survey questions were designed to collate demographics data and participants' knowledge, attitude and perception towards COVID-19.

Results: Overall, 1106 respondents from 16 West African countries, ranging from 1 to 548 with about $11.8 \%$ residing outside the subregion, participated in the survey. The respondents had an average COVID19 knowledge score of $67.82 \pm 8.31$, with knowledge of the disease significantly associated with the country of residence $(P=0.00)$ and marginally so in settlement types $(P=0.05)$. Most respondents (93.4\%) could identify the main COVID-19 symptoms, and $73.20 \%$ would consult a healthcare professional if infected with SARS-CoV-2. Also, $75.2 \%$ of the respondents are willing to receive the COVID19 vaccine, whereas $10.40 \%$ and $14.40 \%$ are unwilling and undecided, respectively. Perceptions of what constitute COVID-19 preventive measures were highly variable. Approximately, $8 \%$ of the respondents felt that their government responded excellently in managing the pandemic while a third felt that the response was just good. Also, more than half (54\%) opined that isolation and treatment of COVID-19 patients is a way of curbing SARS-CoV-2 spread.

Conclusions: Most West Africans have basic knowledge of COVID-19 and showed a positive attitude, with likely proactive practice towards the disease. However, results showed that these varied across countries and are influenced by the types of settlements. Therefore, the health and education authorities in various countries should develop focused measures capturing people in different settlements to improve their preventative measures when designing public health interventions for COVID-19 and any future epidemics or pandemics.

\section{Introduction}

Since the declaration of the novel coronavirus disease-2019 (COVID-19) as a pandemic by the World Health Organization on 11 March 2020, its global burden keeps rising daily [1]. The virus has infected about 199 million people with more than 4.2 million deaths reported worldwide (as of 3 August 2021) [2].

In West Africa, the first case of COVID-19 was confirmed in Nigeria on 27 February 2020 and within 1 month, the virus had spread to all 17 countries [3]. Public awareness plays a major role in preventing the spread of infectious diseases and outbreaks particularly in settings with poor infrastructure and healthcare systems, akin to middle and low-income countries, including those in West Africa, with limited capacity to carter for disease outbreaks [4]. 
Safety guidelines such as regularly sanitizing hands with hydroalcoholic solutions, washing hands with soap and water [5], wearing face masks [3], quarantining of suspected cases, isolation and social distancing, including travel restrictions and banning gatherings of more than ten people [6], have been adopted. Proper adherence to these control measures primarily stems from the publics' knowledge, attitudes, and perception (KAP) of the disease [7]. This study investigated the current knowledge, attitudes and perceptions of the people of West African origin towards the COVID-19 pandemic. The findings therein will be geared towards informed policies and decisions to handle the spread of the virus and curtail the outbreak of the disease in the subregion.

\section{Methods}

\section{Study setting}

This study was conducted in West Africa comprising 16 countries (Figure 1), distributed over an estimated $6,140,000 \mathrm{~km}^{2}$, approximately one-fifth of the African continent and lying between latitudes $4^{\circ} \mathrm{N}$ and $28^{\circ} \mathrm{N}$ and longitudes $15^{\circ} \mathrm{E}$ and $16^{\circ} \mathrm{W}$ [8]. These countries include Benin, Burkina Faso, Cape Verde, Côte d'Ivoire, The Gambia, Ghana, Guinea, Guinea-Bissau, Liberia, Mali, Mauritania, Niger, Nigeria, Senegal, Sierra Leone and Togo [9]. West African population is about 408 million, representing $5 \%$ of the world's population with $56 \%$ under the age of 20 years and $47.7 \%$ living in urban areas [10]. Participants were considered for inclusion in the study if they were of West African origin despite aged 18 years or older.

\section{Questionnaire Design, Piloting and Validation}

An electronic cross-sectional survey was designed to assess the general knowledge, attitude, and perception of West Africans towards the COVID-19 pandemic. The questionnaire was initially drafted in English by our research team and the survey content was critically reviewed. Then it was translated to French, by a professional translator considering there are nine Francophone West African countries. Subsequently, the questionnaire was randomly administered to selected contacts for piloting to assess comprehension, challenges, and minimum time needed in taking the survey. Those who took part in the pilot phase were not members of the research team. Information gathered during this pre-testing phase was used to fine-tune the questionnaire accuracy for better comprehension and estimation of time required to complete the survey before making it available to the study participants online.

\section{Questionnaire's content}

The survey questions (31) were designed to obtain participants' demographic characteristics and assess their knowledge of COVID-19, attitude, and perception (Supplementary material: Survey questions). While some questions required selecting the right answer(s), others needed either a yes/no, true/false or I don't know responses. For questions on attitude and perception, participants were required to respond by scoring on a five-point Likert scale (1, strongly disagree, 2, disagree, 3, neutral, 4, agree, 5, strongly agree). Hence, no question was left open-ended. 


\section{Data Collection Procedure}

A self-administered online questionnaire disseminated over different platforms, including Email, Telegram, Twitter, WhatsApp, Instagram, and Facebook, through a Google Doc URL link was used to collect data. Data from a similar study conducted to examine Gambian adults' perceptions and behaviours in response to COVID-19 social mitigation strategies were also extracted with permission [11]. An email address, checked daily, was provided for participants to seek further information on the study if needed. Data were collected between 29 September and 29 October 2020.

\section{Data Management and Analysis}

Data from the online survey were extracted into Microsoft Excel, cleaned and verified by different individuals. Participants' demographics and research variables were described using descriptive statistics. For the research variables, a correct answer was assigned one point, and an incorrect/unknown answer was assigned zero point. The total knowledge score ranged from zero to 29. Participants' general knowledge, using Bloom's cut-off point, was classified as good [ $80 \%$ and $100 \%]$, moderate [60\% and $79 \%$ ], and poor [ $\leq 59 \%]$ knowledge. Bivariate analysis was performed using Pearson's Chi-square test while Fisher's exact test was carried out to assess the association between demographic variables and COVID19 knowledge, attitude and perception. Ordinal logistic regression was used to investigate the factors affecting COVID-19 knowledge and perception. All significant variables ( $p$-value $<0.05)$ from the bivariate analysis were incorporated into the multivariate analysis to estimate the multivariable model. Also, variables hypothesized to be associated with the level of knowledge and perception of COVID-19 were incorporated in the multivariate model. The statistical significance level was set at $P<0.05$. The Statistical Package for the Social Sciences (SPSS) version 25 [12] was used to perform all analyses.

\section{Ethical Consideration}

This study was approved by the Ethics Committee for Basic and Applied Sciences (ECBAS 063/19-20) at the University of Ghana and conformed to the Declaration of Helsinki ethics guidelines. The raw dataset was saved in a secure password-protected folder and the verified dataset was anonymized to ensure confidentiality. Participation was voluntary, and informed consent was documented on the first page of the survey. Participants who changed their minds in the cause of taking the survey were free to opt-out of submitting the completed questionnaire and their initial responses were not included in the final analyses.

\section{Results}

\section{Sociodemographic characteristics of the respondents}

The sociodemographic characteristics of the respondents are presented in Table 1. A total of 1106 West African adults ( $\geq 18$ years) residing within 975 (87.9\%) and outside $131(12.1 \%)$ of the region, respectively, completed the online survey, with $50.4 \%$ females and $49.5 \%$ males. The average household size was $5.33 \pm 3.853$, with $52.5 \%$ of respondents having between four and six children. Describing their 
area of residence, most (75.9\%) indicated that they lived in an urban setting. Age group composition includes $\leq 20$ years (3.9\%), $21-30$ years ( $41.8 \%), 31-40$ years $(39.1 \%)$ and $\geq 41$ years $(12.2 \%)$, with a mean age of $32.14 \pm 8.359$ years, and missing age for $3 \%$ of the participants. More than half $(51.7 \%)$ of the respondents were married, and $51.4 \%$ identified as Christians. Majority $(90.6 \%)$ had tertiary education and $64.6 \%$ worked in the public or private sector, apart from health care professionals (11.4\%). Table 1 shows the distribution of participants by country of origin with the highest number (49.6\%) of respondents from Nigeria. 
Table 1

Sociodemographic factors of the respondents

\begin{tabular}{|c|c|c|c|}
\hline Variables & & $\begin{array}{l}\text { Number of respondents } \\
(\%)\end{array}$ & Mean \pm SE \\
\hline \multirow[t]{7}{*}{ Country of residence } & Nigeria & $470(42.5)$ & \\
\hline & Ghana & $184(16.6)$ & \\
\hline & The Gambia & $179(16.2)$ & \\
\hline & Senegal & $75(6.8)$ & \\
\hline & Liberia & $28(2.5)$ & \\
\hline & Other WAC & $39(3.5)$ & \\
\hline & Outside WA & $131(11.8)$ & \\
\hline \multirow[t]{2}{*}{ Gender } & Male & $547(49.5)$ & \\
\hline & Female & $557(50.5)$ & \\
\hline \multirow[t]{4}{*}{ Age group } & $\leq 20$ & $43(3.9)$ & \\
\hline & $21-30$ & $462(41.8)$ & \\
\hline & $31-40$ & $432(39.1)$ & \\
\hline & $\geq 41$ & 135 (12.2) & \\
\hline Mean Age & & 1071 & $\begin{array}{l}32.14 \pm \\
8.359\end{array}$ \\
\hline \multirow[t]{3}{*}{ Educational status } & Senior Secondary & $92(8.3)$ & \\
\hline & Tertiary & $1002(90.6)$ & \\
\hline & Vocational & $9(0.8)$ & \\
\hline $\begin{array}{l}\text { Total years of formal } \\
\text { education }\end{array}$ & & 1070 & $\begin{array}{l}17.28 \pm \\
4.374\end{array}$ \\
\hline \multirow[t]{3}{*}{ Household size } & $1-3$ & $282(26.3)$ & \\
\hline & $4-6$ & $563(52.5)$ & \\
\hline & $>6$ & $228(21.2)$ & \\
\hline Mean household size & & 1073 & $5.33 \pm 3.853$ \\
\hline \multirow[t]{2}{*}{ Area description } & Urban & $693(75.9)$ & \\
\hline & Rural & $25(2.6)$ & \\
\hline
\end{tabular}

WA: West African; WAC: West African Countries; Religious affiliation (Others): Traditional religion and no response; Marital status (Others): Divorced, widowed and separated. 


\begin{tabular}{|c|c|c|c|}
\hline \multicolumn{2}{|l|}{ Variables } & \multirow{2}{*}{$\begin{array}{l}\text { Number of respondents } \\
\text { (\%) }\end{array}$} & \multirow[t]{2}{*}{ Mean \pm SE } \\
\hline & Suburban & & \\
\hline \multirow[t]{4}{*}{ Occupation } & Student & $186(16.8)$ & \\
\hline & $\begin{array}{l}\text { Public/Private } \\
\text { servant }\end{array}$ & $714(64.6)$ & \\
\hline & Unemployed & $74(6.7)$ & \\
\hline & Health Professionals & $126(11.4)$ & \\
\hline \multirow[t]{3}{*}{ Marital Status } & Single & $499(46.5)$ & \\
\hline & Married & $554(51.7)$ & \\
\hline & Others & $19(1.8)$ & \\
\hline \multirow[t]{3}{*}{ Religious affiliation } & Christian & $568(80.3)$ & \\
\hline & Islam & $125(17.7)$ & \\
\hline & Others & $12(2.0)$ & \\
\hline
\end{tabular}

Knowledge of respondents about COVID-19: Causative agent, means of transmission, main symptoms, high-risk group and places, and who should be tested.

The respondents' knowledge score on COVID-19 is presented in Table 2, with an average knowledge score of $67.82 \pm 8.31$. The knowledge score was significantly associated with the country of residence $(P=$ $0.000)$ and marginally with settlement type $(P=0.05)$, but not with gender, age, occupation, religion, marital and educational status. 
Table 2

Knowledge score of the respondents and multiple linear regression on factors associated with COVID-19 knowledge.

\begin{tabular}{|c|c|c|c|c|}
\hline Variables & & Knowledge score (\%) & Coefficients \pm SE & P-value \\
\hline \multirow[t]{7}{*}{ Country of residence } & Nigeria & $68.50 \pm 8.23$ & $-0.649 \pm 0.137$ & 0.000 \\
\hline & Ghana & $68.33 \pm 7.57$ & & \\
\hline & The Gambia & $69.06 \pm 8.68$ & & \\
\hline & Senegal & $66.86 \pm 8.39$ & & \\
\hline & Liberia & $69.47 \pm 8.86$ & & \\
\hline & Other WAC & $62.03 \pm 8.70$ & & \\
\hline & Outside WA & $70.49 \pm 7.75$ & & \\
\hline \multirow[t]{2}{*}{ Gender } & Male & $67.88 \pm 8.72$ & $0.388 \pm 0.635$ & 0.32 \\
\hline & Female & $68.44 \pm 8.20$ & & \\
\hline \multirow[t]{4}{*}{ Age group } & $\leq 20$ & $68.37 \pm 7.94$ & $0.395 \pm 0.319$ & 0.86 \\
\hline & $21-30$ & $68.27 \pm 8.89$ & & \\
\hline & $31-40$ & $67.90 \pm 8.31$ & & \\
\hline & 41 and above & $68.63 \pm 7.61$ & & \\
\hline \multirow[t]{3}{*}{ Area description } & Urban & $69.58 \pm 8.33$ & $0.444 \pm 0.373$ & 0.05 \\
\hline & Rural & $69.36 \pm 8.11$ & & \\
\hline & Suburban & $68.01 \pm 8.11$ & & \\
\hline \multirow[t]{3}{*}{ Religious affiliation } & Christian & $67.83 \pm 9.61$ & $1.010 \pm 0.645$ & 0.75 \\
\hline & Islam & $69.77 \pm 9.46$ & & \\
\hline & Others & $29.29 \pm 3.57$ & & \\
\hline \multirow[t]{3}{*}{ Educational status } & Senior Secondary & $29.30 \pm 3.63$ & $2.104 \pm 1.475$ & 0.07 \\
\hline & Tertiary & $33.50 \pm 3.32$ & & \\
\hline & Vocational & $29.67 \pm 3.64$ & & \\
\hline \multirow[t]{2}{*}{ Occupation } & Student & $29.19 \pm 3.58$ & $2.104 \pm 1.475$ & 0.06 \\
\hline & Public/Private servant & $28.00 \pm 4.63$ & & \\
\hline
\end{tabular}

WA: West African; WAC: West African Countries; Religion (Others): Traditional religion and no response; Marital status (Others): Divorced, widowed and separated. 


\begin{tabular}{|c|c|c|c|c|}
\hline \multicolumn{2}{|l|}{ Variables } & \multirow{2}{*}{$\begin{array}{l}\text { Knowledge score (\%) } \\
29.70 \pm 3.51\end{array}$} & \multirow[t]{2}{*}{ Coefficients \pm SE } & \multirow[t]{2}{*}{ P-value } \\
\hline & Unemployed & & & \\
\hline & Health Professionals & $68.31 \pm 8.61$ & & \\
\hline \multirow[t]{2}{*}{ Marital Status } & Single & $67.98 \pm 8.31$ & $-0.187 \pm 0.660$ & 0.63 \\
\hline & Married & $69.65 \pm 7.65$ & & \\
\hline
\end{tabular}

Notably, on the question on "How is SARS-CoV-2 is transmitted?", $80.80 \%$ of the respondents correctly agreed that the disease can be transmitted by respiratory droplets when an infected person coughs, sneezes or speaks. Additionally, $73.40 \%$ correctly agreed that SARS-CoV-2 can be contracted by touching contaminated surfaces and then touching one's face (Fig. 2). Regarding clinical symptoms, most of the respondents (93.40\%) agreed that chest pain, fever, dry cough, shortness of breath are the main symptoms of COVID-19. However, only $31.30 \%$ know that, unlike the common cold, stuffy nose, runny nose, and sneezing are less common in persons with COVID-19. The proportion of respondents who correctly identified the people most at risk of contracting COVID-19 is 75.1\%: people who work in high-risk settings such as hospitals, prisons and other closed settings, $83.7 \%$ : overseas travellers, $71.6 \%$ : researchers whose research involves close contact with the causative virus or people with COVID-19 and 72.8\%: people with compromised immune system. In addition, $62.8 \%$ correctly identified old age, underlying chronic diseases and obesity as predisposing factors for severe COVID-19 conditions. Most of the respondents $(80.10 \%)$ acquired information about COVID-19 from the mainstream media while $66.70 \%, 64.70 \%$ and $45.5 \%$ acquired the information from the internet, social media and their friends and family members, respectively (Fig. 3).

\section{Attitude toward COVID-19: Vaccine acceptance, worried about getting infected and what to do if infected with SARS-CoV-2}

The willingness of the respondents to receive COVID-19 vaccine is presented in Table 3. Overall, $75.4 \%$ are willing to accept COVID-19 vaccine with the highest level of acceptance from those residing in Ghana (92.4\%) and the lowest from The Gambian (38.1\%) residents, who were mostly (41.5\%) undecided regarding COVID-19 vaccine acceptance. The willingness to accept COVID-19 vaccine was significantly associated $(P=0.000)$ with country of residence, age category, religious affiliation, occupation, educational status $(P=0.013)$ and marital status $(P=0.026)$, but not gender $(P=0.89)$ and type of settlement $(P=0.95)$. 
Table 3

Willingness to accept COVID 19 vaccine.

\begin{tabular}{|c|c|c|c|c|c|}
\hline \multicolumn{2}{|l|}{ Variables } & $\begin{array}{l}\text { Yes } \\
(75.1 \%)\end{array}$ & $\begin{array}{l}\text { No } \\
(9.9 \%)\end{array}$ & $\begin{array}{l}\text { Undecided } \\
14.6(\%)\end{array}$ & P-value \\
\hline \multirow{8}{*}{ Country of residence } & & & & & \multirow{8}{*}{0.000} \\
\hline & Nigeria & 398 (84.7) & $30(6.4)$ & $42(8.9)$ & \\
\hline & Ghana & $170(92.4)$ & $6(3.3)$ & $8(4.3)$ & \\
\hline & Senegal & $40(54.1)$ & $18(24.3)$ & $16(21.6)$ & \\
\hline & Other WAC & $29(74.4)$ & $5(12.8)$ & $5(12.8)$ & \\
\hline & Gambia & $67(38.1)$ & $36(20.5)$ & $73(41.5)$ & \\
\hline & Liberia & $16(57.1)$ & $8(28.6)$ & $4(14.3)$ & \\
\hline & Outside WA & $110(84.6)$ & $6(4.6)$ & $14(10.8)$ & \\
\hline \multirow[t]{2}{*}{ Gender } & Male & $414(75.8)$ & $55(10.0)$ & $77(14.1)$ & \multirow[t]{2}{*}{0.89} \\
\hline & Female & $414(74.6)$ & $59(10.6)$ & $82(14.8)$ & \\
\hline \multirow[t]{4}{*}{ Age group } & $\leq 20$ & $28(66.7)$ & $8(19)$ & $6(14.3)$ & \multirow[t]{4}{*}{0.000} \\
\hline & $21-30$ & $318(69)$ & $61(13.2)$ & $82(17.8)$ & \\
\hline & $31-40$ & $352(81.5)$ & $37(8.6)$ & $43(10)$ & \\
\hline & 41 and above & $115(85.2)$ & $5(3.7)$ & $15(11.1)$ & \\
\hline \multirow[t]{3}{*}{ Area description } & Urban & $574(83.1)$ & $57(8.2)$ & $60(8.7)$ & \multirow[t]{3}{*}{0.95} \\
\hline & Rural & $20(80)$ & $2(8)$ & $3(12)$ & \\
\hline & Suburban & $163(83.2)$ & $18(9.2)$ & $15(7.7)$ & \\
\hline \multirow[t]{3}{*}{ Religious affiliation } & Christian & $528(93)$ & $17(3)$ & $23(4)$ & \multirow[t]{3}{*}{$0.000^{*}$} \\
\hline & Islam & $92(74.8)$ & $17(13.8)$ & $11.4(11.4)$ & \\
\hline & Others & $11(91.7)$ & - & $1(8.3)$ & \\
\hline \multirow[t]{3}{*}{ Educational status } & Senior Secondary & $57(62.6)$ & 17(18.7) & 17(18.7) & \multirow[t]{3}{*}{0.013} \\
\hline & Tertiary & $764(76.4)$ & $95(9.5)$ & $141(14.1)$ & \\
\hline & Vocational & $7(77.8)$ & $2(22.2)$ & 0 & \\
\hline \multirow[t]{2}{*}{ Occupation } & Student & $133(71.9)$ & $31(16.8)$ & $21(11.4)$ & \multirow[t]{2}{*}{$0.000^{*}$} \\
\hline & Public/Private servant & $553(77.7)$ & $60(8.4)$ & 99 (13.9) & \\
\hline
\end{tabular}




\begin{tabular}{|c|c|c|c|c|c|}
\hline \multicolumn{2}{|l|}{ Variables } & $\begin{array}{l}\text { Yes } \\
(75.1 \%)\end{array}$ & $\begin{array}{l}\text { No } \\
(9.9 \%)\end{array}$ & $\begin{array}{l}\text { Undecided } \\
14.6(\%)\end{array}$ & \multirow[t]{3}{*}{ P-value } \\
\hline & Unemployed & $31(41.9)$ & $16(21.6)$ & $27(36.5)$ & \\
\hline & Health Professionals & $110(87.3)$ & $6(4.8)$ & $10(7.9)$ & \\
\hline \multirow[t]{3}{*}{ Marital Status } & Single & $370(74.4)$ & $63(12.7)$ & $64(12.9)$ & \multirow[t]{3}{*}{0.026} \\
\hline & Married & $424(76.5)$ & $48(8.7)$ & $82(14.8)$ & \\
\hline & Others & $19(100)$ & - & - & \\
\hline Total & & $828(75.2)$ & $114(10.4)$ & $159(14.4)$ & \\
\hline
\end{tabular}

In addition, most of the respondents (65.30\%) were worried that they or someone they know may contract COVID-19 (Fig. 4A). Similarly, most of the respondents (73.20\%) reported willingness to consult health care professionals while $14.50 \%, 6.40 \%$ and $5.60 \%$ will go on self-isolation, self-medication/herbal treatment, or other means of treatment, respectively, if they contract the disease (Fig. 4B).

\section{Perceptions on COVID-19: How to prevent getting infected and/or spreading the virus and perception of government intervention}

Most of the respondents (96.7\%) perceived that avoiding touching your eyes, nose, and mouth with unwashed hands helps prevent SARS-CoV-2 spread. Similarly, 94.6\%, 93.6\% and $92.6 \%$ respectively perceived that 'the use of alcohol-based hand sanitisers, covering one's mouth when coughing or sneezing and avoiding close contact with sick people' could prevent contracting or spreading SARS-CoV-2 (Fig. 5A). On the other hand, perceptions of what constitute COVID-19 preventive measures were highly variable, including getting a vaccination against flu (62.5\%), taking food supplements e.g., Vitamin C (53.2\%), eating garlic (41.6\%), ginger or drinking lemon or neem tea $(26.4 \%)$, steaming or taking a hot bath/sauna (25.1\%), taking antibiotics (19.4\%), gargling mouthwash and/or saline water and staying under the sun (14.6\%) (Fig. 5A). On treatment and management of COVID-19 patients, $86.1 \%$ agreed that isolation and treatment of COVID-19 patients are best for managing the disease (Fig. 5B). Additionally, $8 \%$ perceived that their governments' response to the pandemic was "Excellent" while $20 \%$ and $34 \%$ stated the response was "Very good" and "Good", respectively (Fig. 5C) and more than half of the respondents felt that prompt measures were taken by their government to curb the SARS-CoV-2 spread.

\section{Discussion}

Risk perception is key in defining disease prevention, control, treatment, eradication, or elimination [13]. Varied COVID-19 burdens and responses have been reported globally, partly attributable to the varied 
knowledge, attitude and perception of the disease, which generally define risk perception [14]. As a novel disease, people's perception will probably border on the availability of quality and reliable data generated through research, public engagement and education, as well as the prevalence of the disease in different geographical locations. Despite the potential for under-reporting across Africa, the low case and mortality reports in official realms in Africa [15] underscores the need for this survey, which aims to ascertain the knowledge, attitude and perception of West Africans towards the disease. Generally, males are more inclined to fill out surveys than females [16]; however, there was one per cent more female participants in this survey than male [17]. Additionally, analysis of the results indicated that the majority of the respondents were either in the tertiary institution or had attained tertiary level education. By and large, the nature of the present survey could explain these findings; being an online survey, respondents were more likely to be educated. Thus, their respective participation might have been influenced by their basic understanding of the pandemic, ability to assimilate and interpret circulating information, and potential to form meaningful opinions [18].

From our survey, country of residence and type of settlement significantly correlated with knowledge of the pandemic. This significant variation could be attributed to the huge variation in the breadth of mainstream media (e.g. radio, TV) coverage and availability of locally generated and globally available information, local disease burden and the ability to infer from available information $[14,19]$. This may also explain the variation in the depth of content and their ability to identify groups of people most at risk of COVID-19. This is the medium of information exchange, and this study shows the immense contribution of mainstream media as an outlet for information on the pandemic. The majority of the respondents were between 21-30 years followed by those 31-40 years of age. This group of participants, under age 40, seem to be the most active on social media [20]; however, inferring from the results, mainstream media was the best information outlet, followed by social media in West Africa. This is despite the high prevalence of misinformation and conspiracy theories around COVID-19 within the social media ecosystem, owing to the fact that most households own a mobile phone in Africa [21] and social media is a powerful source of information. The disease prevalence can also inform people, as individuals with close contact with the disease, including frontline health workers, researchers, and others who have had the unfortunate experience of losing loved ones to COVID-19 or witnessed relatives with mild to severe COVID-19 symptoms will much more appreciate the disease severity. This may have influenced their knowledge of the disease, which may explain the knowledge scores observed, and the overall knowledge on the COVID-19 affects attitude towards the pandemic [20]. The knowledge scores observed may be attributable to the success of sensitization campaigns such as that by the West African Health Organization $[22,23]$.

The attitude of respondents towards COVID-19 was measured in many ways, including their fear of contracting the virus and their response to such an event. Generally, the majority of respondents dreaded the thought of they or any of their relations contracting the virus. The concern of contracting SARS-CoV-2 by most participants is a testament to their knowledge of consulting health professionals at the onset of COVID-19 symptoms [24]. Willingness to accept a COVID-19 vaccine was another means of ascertaining the attitude of respondents to the disease. In this study the willingness to accept a vaccine was generally 
good; however, of concern is the influence that those unwilling to accept the vaccine may have on those that are undecided, who unfortunately constituted more than the unwilling [25]. These uncertain individuals are not necessarily part of the anti-vaccine movement but may need more compelling information showing the need for a vaccine, that is individual and population-level benefits. Such individuals have vaccine safety issues or probably still think the virus's existence is a hoax $[25,26]$. Also, the overall attitude of respondents is significantly associated with age. Age reflects an awareness of the importance of understanding relevant information ${ }^{17}$ and may explain the significant association between age and attitude towards the pandemic. The attitude of respondents is associated significantly with religion. Religion is quite instrumental in knowledge acquisition, attitude and perception formation, much so in this pandemic [27]. Some individuals believe that the pandemic is a supernatural purge that will culminate in the end times. This may explain the significant association with religion. Conversely, existing religious inequalities have been exacerbated by COVID-19 and may affect efforts to curb the pandemic [28] due to individuals' attitudes regarding the disease based on their religious predisposition. Although knowledge score may be high, attitude towards the disease can also be significantly affected by perception [19].

The World Health Organization has stipulated guidelines and safety practices to prevent and mitigate SARS-CoV-2 transmission and progression, including handwashing and wearing face masks [29]. From this survey, most of the respondents seem conversant with these, as was evident in their perception of prioritizing safety practices. Additionally, the importance of traditional medicine was evident in the responses. Furthermore, governments have introduced policies and measures such as temporary travelling restrictions, quarantine of international travellers, wearing face masks, and social distancing, to curb the infection; these decisions influence perception of the disease [20]. This can be inferred from the fact that most of our respondents have a level of formal education, which could translate to an understanding of the government intervention strategies, as about one-third of them deem government intervention as 'good'.

The findings of this survey must be interpreted with a few limitations in mind. This online survey may have resulted in a selection bias for those with higher formal education and acumen for internet and social media; thus, limiting the breadth of respondents across the sociodemographic. Also, the nature of the survey might have favoured respondents (both high and low formal education) in the major cities where internet and mobile network coverage is high; thus, alienating people without internet access or those who cannot access the media. However, this will not invalidate the findings of this survey. Finally,

this survey is a cross-sectional study and cannot allow any inferences to be made on causality and temporality, concerning perception and the sociodemographic factors.

\section{Conclusion}

Most West Africans have basic knowledge of COVID-19 and a positive attitude, with likely proactive practice towards the disease. However, results showed that these varied across countries and are influenced by the types of settlements. Therefore, the health and education authorities in various 
countries should tailor public health interventions towards enforcing preventative measures against this pandemic, with a special focus on the most impoverished communities. The present survey highlights the need for a more extensive survey that cuts across the socio-demographic divide to properly ascertain the impact of COVID-19 interventions and general knowledge, including in-person questionnaire administration for wider coverage.

\section{Abbreviations}

COVID-19: Coronavirus disease 2019

SARS-CoV-2: Severe Acute Respiratory Syndrome Corona Virus 2

URL: Uniform Resource Locator

ECBAS: Ethics Committee for Basic and Applied Sciences

\section{Declarations}

\section{Ethics approval and consent to participate}

This study was approved by the University of Ghana Ethics Committee for Basic and Applied Sciences (ECBAS 063/19-20) and conformed to the Declaration of Helsinki ethics guidelines. Participation was voluntary, and an informed consent statement on the first page of the survey was documented from individuals greater than or equal to 18 years of age. Participants who changed their minds in the cause of taking the survey were free to opt-out of submitting the completed questionnaire and their initial responses were not included in the final analyses. All methods were carried out in accordance with the relavant guidelines and regulations guiding reseach invoving human subjects and the responses were anonymised.

\section{Consent for publication}

All authors give their consent for the publication of this work.

\section{Availability of data and materials}

The dataset used and/or analysed during the current study are available from the corresponding author on a reasonable request.

\section{Competing interests}

The authors declare that they have no competing interests.

\section{Funding}

Not applicable as the study was not funded. 


\section{Authors' contribution}

AJU conceptualized the study. AJU, ALDZ, KT, NNN, and LP were involved in the study design. AJU, ALDZ, $\mathrm{KT}$, NNN, MAO, IKF, ML, BK, and LP were involved in the creation and constructive review of the survey instrument (the questionnaire). AJU, ALDZ, KT, OO, IKF, CAA, ML, NNN, BK, FNO, ANH, MAO, and LP, distributed the survey link online. AJU, IKF, BK, FNO, and ANH were involved in the initial cleaning of the results while IKF and AJU performed the analyses and critically appraised the results to identify key themes. ALDZ, KT, OO, CAA, ML, and AJU wrote the initial draft of the manuscript. LP and LNA substantively revised the manuscript. All authors reviewed the final draft and approved it for submission.

\section{Acknowledgement:}

We thank all Ms Gilliane Elsa Pouamou for translating the original manuscript from English to the French language and the survey participants for their participation in the study.

\section{References}

1. World Health Organization. WHO Director-General's opening remarks at the media briefing on COVID19 - 11 March 2020. 2020. https://www.who.int/director-general/speeches/detail/who-directorgeneral-s-opening-remarks-at-the-media-briefing-on-covid-19--11-march-2020. Accessed 9 Feb 2021.

2. Worldometer.info/coronavirus. COVID Live Update: 199,764,057 Cases and 4,252,595 Deaths from the Coronavirus - Worldometer. 2021. https://www.worldometers.info/coronavirus/. Accessed 3 Aug 2021.

3. Amzat J, Aminu K, Kolo VI, Akinyele AA, Ogundairo JA, Danjibo MC. Coronavirus outbreak in Nigeria: Burden and socio-medical response during the first 100 days. Int J Infect Dis. 2020,98:218-24. doi:10.1016/j.ijid.2020.06.067.

4. Durizzo K, Asiedu E, Van der Merwe A, Van Niekerk A, Günther I. Managing the COVID-19 pandemic in poor urban neighborhoods: The case of Accra and Johannesburg. World Dev. 2021,137.

5. Bonful HA, Addo-Lartey A, Aheto JMK, Ganle JK, Sarfo B, Aryeetey R. Limiting spread of COVID-19 in Ghana: Compliance audit of selected transportation stations in the Greater Accra region of Ghana. PLoS One. 2020,15:e0238971. doi:10.1371/journal.pone.0238971.

6. Taboe HB, Salako K V., Tison JM, Ngonghala CN, Glèlè Kakaï R. Predicting COVID-19 spread in the face of control measures in West Africa. Math Biosci. 2020,328:108431. doi:10.1016/j.mbs.2020.108431.

7. Zhong BL, Luo W, Li HM, Zhang QQ, Liu XG, Li WT, et al. Knowledge, attitudes, and practices towards COVID-19 among Chinese residents during the rapid rise period of the COVID-19 outbreak: A quick online cross-sectional survey. Int J Biol Sci. 2020,16:1745-52.

8. Food and Agricultural Organization of the United Nations. Integrating crops and livestock in West Africa. http://www.fao.org/3/x6543e/X6543E01.htm\#ch1.1. Accessed 9 Feb 2021. 
9. World Atlas. West African Countries. 2021. https://www.worldatlas.com/geography/west-africancountries.html. Accessed 4 Aug 2021.

10. Worldometer. Population of Western Africa (2021). 2021. https://www.worldometers.info/worldpopulation/western-africa-population/. Accessed 9 Feb 2021.

11. Lowe M. Using rapid online survey to assess public perceptions of COVID-19 in Gambia. Pan Afr Med J. 2020,35 Figure 1:1-2.

12. IBM Corp. IBM SPSS Statistics for Windows. 2017.

13. Aerts C, Revilla M, Duval L, Paaijmans K, Chandrabose J, Cox H, et al. Understanding the role of disease knowledge and risk perception in shaping preventive behavior for selected vector-borne diseases in Guyana. PLoS Negl Trop Dis. 2020,14:e0008149.

14. Gollust SE, Nagler RH, Fowler EF. The Emergence of COVID-19 in the US: A Public Health and Political Communication Crisis. J Health Polit Policy Law. 2020,45:967-81.

15. World Health Organization. WHO Coronavirus Disease (COVID-19) Dashboard I WHO Coronavirus Disease (COVID-19) Dashboard. 2021. https://covid19.who.int/. Accessed 23 Jan 2021.

16. Bowale A, Abayomi A, Idris J, Omilabu S, bdus-Salam I, Adebayo B, et al. Clinical presentation, case management and outcomes for the first 32 COVID-19 patients in Nigeria. panafrican-medjournal.com. 2020,35.

17. Mulder J, de Bruijne M. Willingness of Online Respondents to Participate in Alternative Modes of Data Collection. Surv Pract. 2019,12:1-11.

18. Diaz-Quijano FA, Martínez-Vega RA, Rodriguez-Morales AJ, Rojas-Calero RA, Luna-González ML, Díaz-Quijano RG. Association between the level of education and knowledge, attitudes and practices regarding dengue in the Caribbean region of Colombia. BMC Public Health. 2018,18:143.

19. Bol D, Giani M, Blais A, Loewen PJ. The effect of COVID-19 lockdowns on political support: Some good news for democracy? Eur J Polit Res. 2020.

20. Oleribe O, Ezechi O, Osita-Oleribe P, Olawepo O, Musa AZ, Omoluabi A, et al. Public perception of COVID-19 management and response in Nigeria: A cross-sectional survey. BMJ Open. 2020,10:e041936.

21. Silver $L$, Johnson $C$. Basic mobile phones more common than smartphones in sub-Saharan Africa I Pew Research Center. Internet connectivity seen as having positive impact on life in sub-Saharan Africa. 2018.

22. Federal Ministry for Economic Cooperation and Development. Supporting ECOWAS and Nepal in fighting COVID-19 - Healthy DEvelopments - BMZ. 2020. https://health.bmz.de/events/In_focus/development_cooperation_covid_19/index.html. Accessed 21 Mar 2021.

23. Organization for Economic Cooperation and Development. When a global virus meets local realities: Coronavirus (COVID-19) in West Africa. 2020. http://www.oecd.org/coronavirus/policyresponses/when-a-global-virus-confronts-local-realities-coronavirus-covid-19-in-west-africa8af7f692/. Accessed 21 Mar 2021. 
24. Centre for Disease Control and Prevention. What to Do If You Are Sick | CDC. U.S. Department of Health \& Human Services. 2021. https://www.cdc.gov/coronavirus/2019-ncov/if-you-are-sick/stepswhen-sick.html. Accessed 3 Aug 2021.

25. Jerving S. 4 out of 5 Africans would take a COVID-19 vaccine: Africa CDC survey | Devex. 2020.

26. Lewis JR. What Is Driving the Decline in People's Willingness to Take the COVID-19 Vaccine in the United States? JAMA Heal Forum. 2020,1:e201393.

27. World Health Organization. Practical considerations and recommendations for religious leaders and faith-based communities in the context of COVID-19. 2020.

28. Institute of development studies. Religious inequalities and the impact of Covid-19 | Institute of Development Studies. 2020.

29. World Health Organization. Coronavirus disease (COVID-19): Cleaning and disinfecting surfaces in non-health care settings. 2020.

\section{Figures}

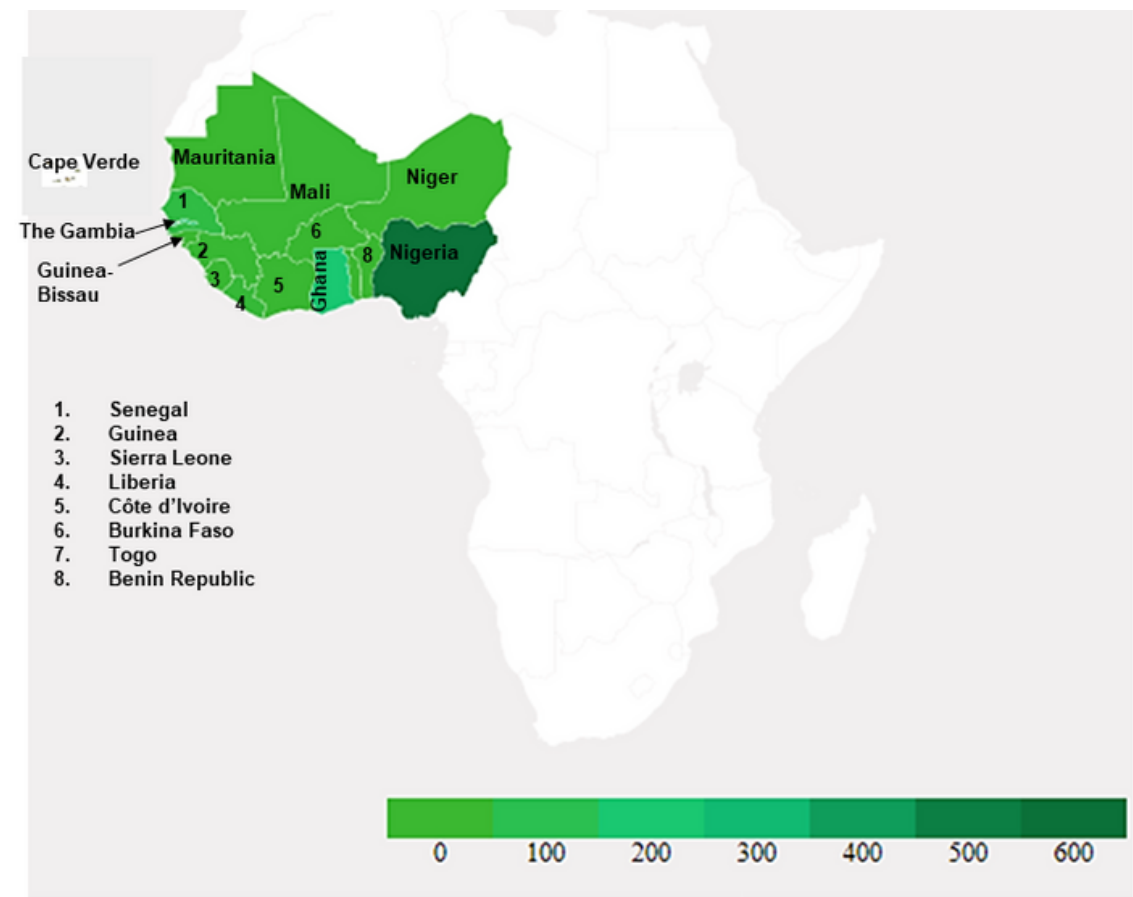

\section{Figure 1}

Country of Origin of Respondents. The shaded areas represent the 16 West African countries and the intensity of the green colour indicates the number of respondents from the respective countries. 


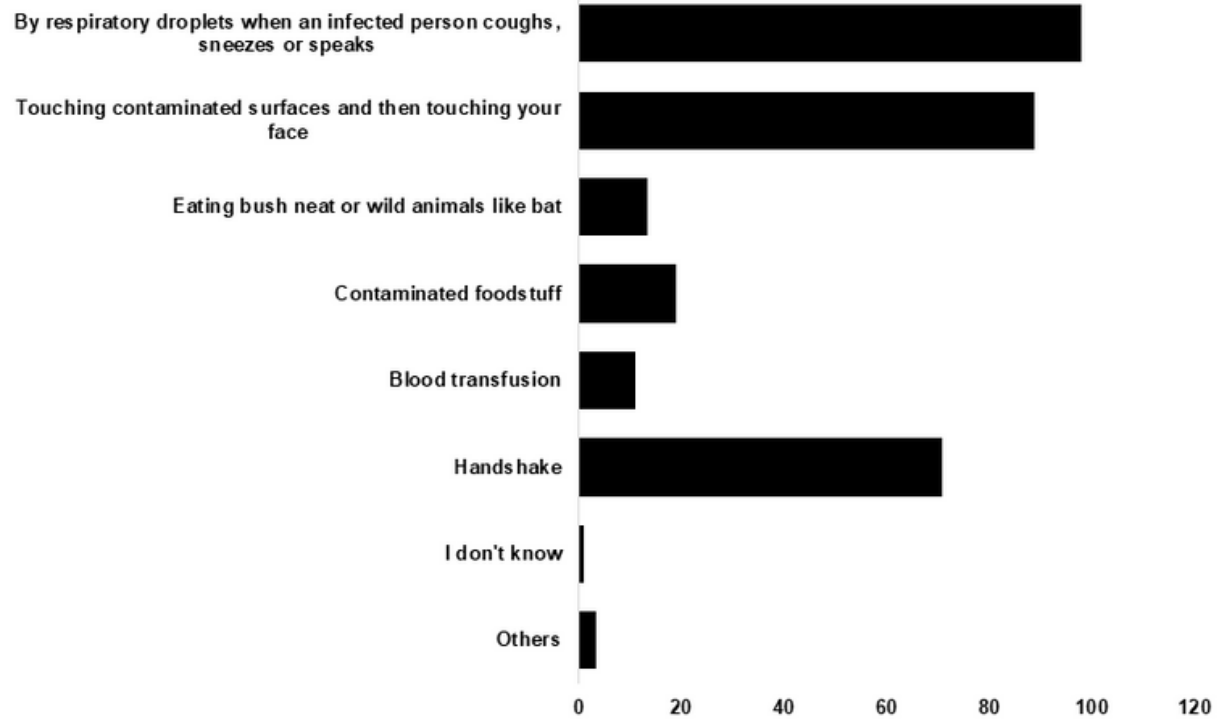

Figure 2

Participants response to "How is SARS-CoV-2 is transmitted?"

100

90

80

70

60

50

40

30

20

10

0

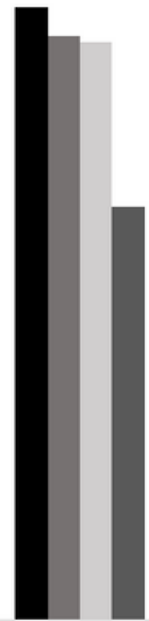

Nigeria

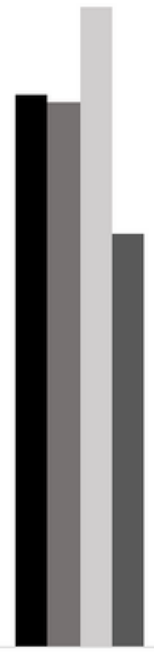

Ghana

- Internet

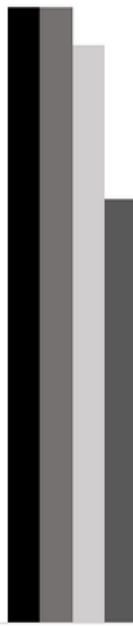

Senegal

- Social media

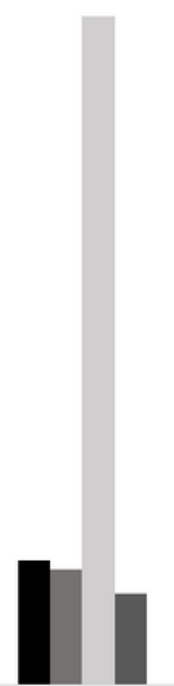

The Gambia

Mains tream media

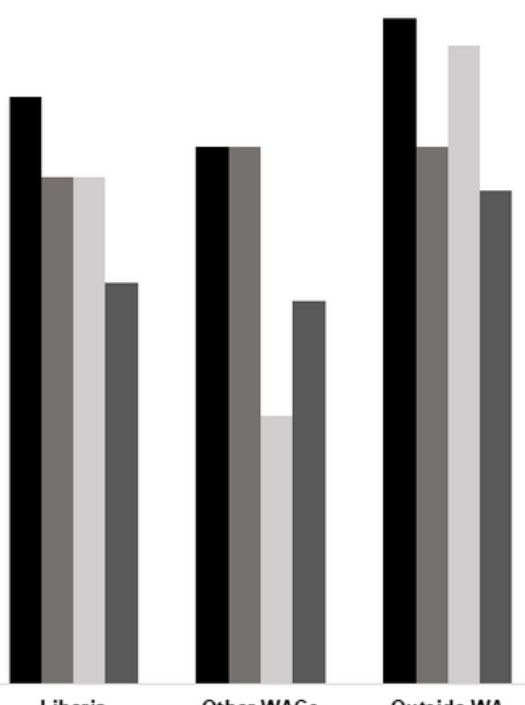

Liberia

Other WACs

Outside WA 
Figure 3

Participants sources of COVID-19 Information (Internet include: Journal articles, virtual conferences, online information, social media include: WhatsApp, Twitter, Instagram, Facebook, etc., Mainstream media: Television, Radio and Print media).
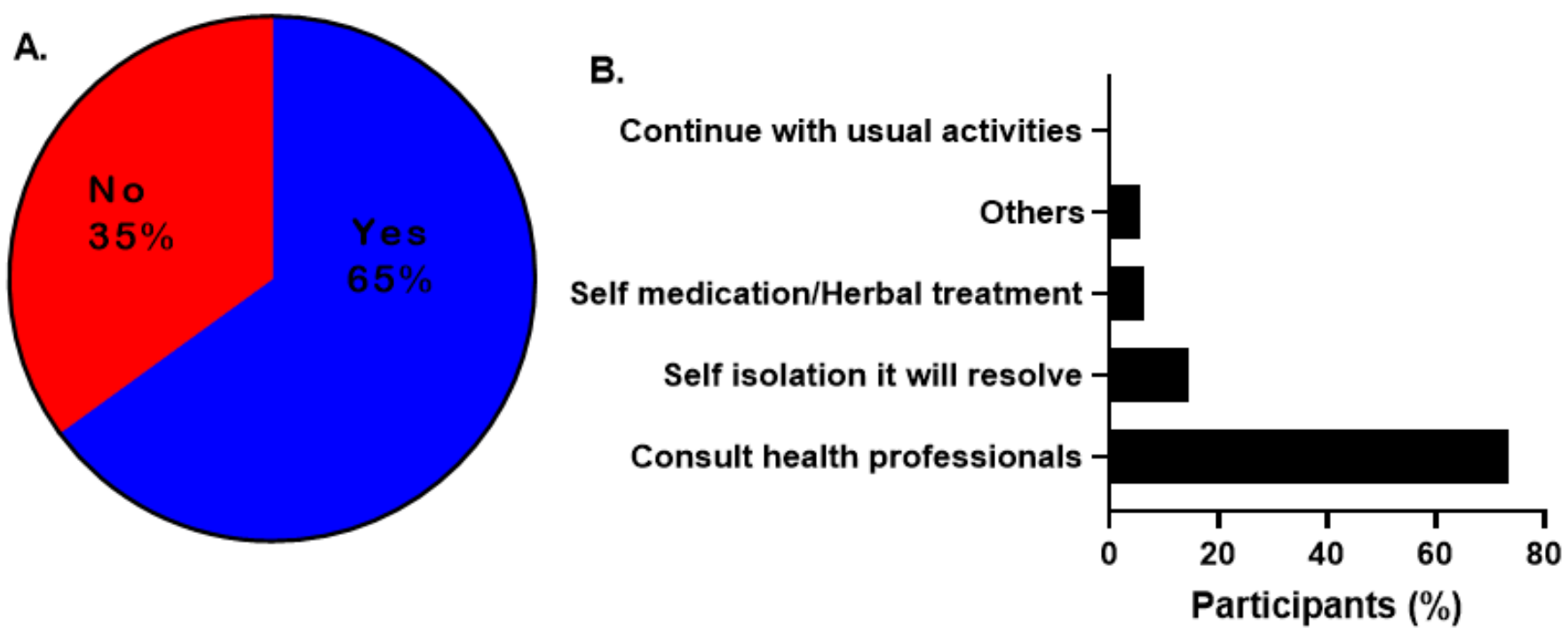

Figure 4

Attitude of the respondents toward COVID-19. (A) Worried about contracting SARS-CoV-2 (B) Response to "What will you do if you contract COVID-19?". 
A.

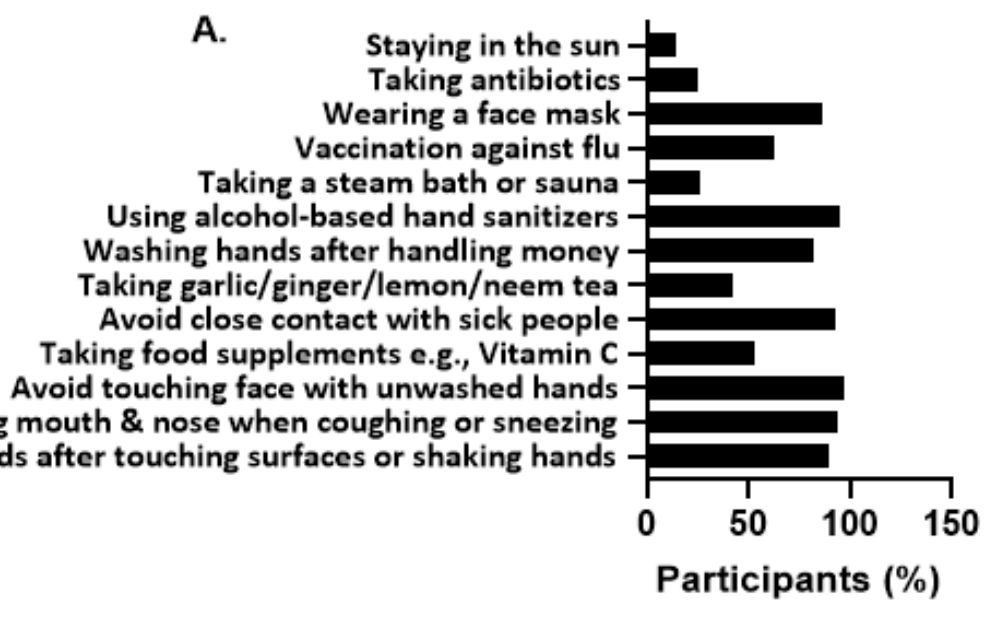
Using alcohol-based hand sanitizers Washing hands after handling money Taking garlic/ginger/lemon/neem tea Avoid close contact with sick people
B.

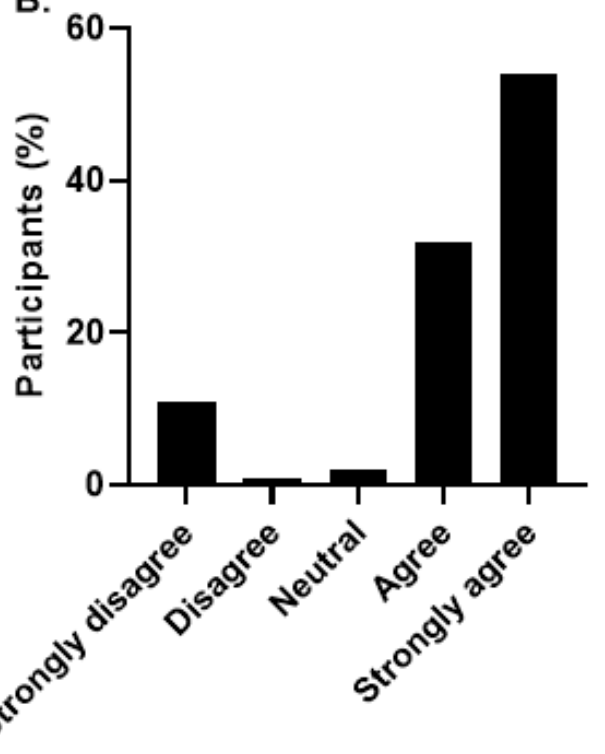

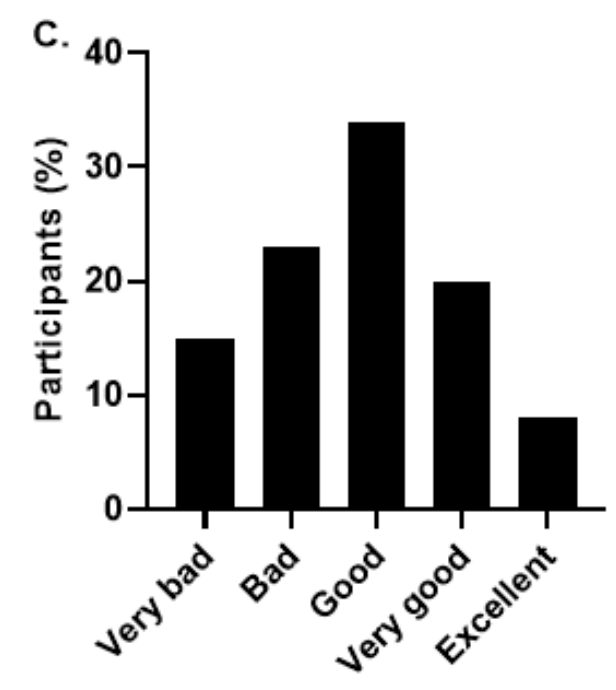

Taking food supplements e.g., Vitamin C Avoid touching face with unwashed hands Covering mouth $\&$ nose when coughing or sneezing Washing hands after touching surfaces or shaking hands Washing hands after touching su

Figure 5

Perceptions on COVID-19 control and governments' response (A) Preventive measures (B) Response to "Isolation and treatment of COVID-19 patients is best for the management of the COVID-19" (C) Government's response to COVID-19 pandemic.

\section{Supplementary Files}

This is a list of supplementary files associated with this preprint. Click to download.

- Surveyquestions.docx 